\title{
Effects on Oil/Moisture Changes Using Commercial Brand Cosmetics versus DIY Cosmetics in Women in their 20s and 30 s with Dry Skin
}

\author{
Suyeun Lim, Ki Han Kwon* \\ Division of Beauty Arts Care, Department of Practical Arts, Graduate School of Culture and Arts, Dongguk University, Seoul, Korea
}

\author{
"Corresponding author: Ki Han Kwon, \\ Division of Beauty Arts Care, Department of \\ Practical Arts, Graduate School of Culture \\ and Arts, Dongguk University, 30, Pildong- \\ ro 1-gil, Jung-gu, Seoul 04620, Korea \\ Tel.: +82222603606 \\ Fax: +82 222603741 \\ Email: kihan.kwon@dongguk.edu
}

Received July 04, 2020

Revised August 07, 2020

Accepted August 10, 2020

Published September 30, 2020

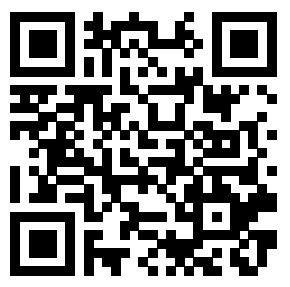

\begin{abstract}
Purpose: With the increased interest in skincare and consumption of natural products, the improvement of expectations for internal health and external beauty has also affected the Do It Yourself (DIY) cosmetics market. Therefore, this study aimed to present the possibility of future development of DIY cosmetics through experiments that compare and analyze the effects of DIY cosmetics made by the company itself with high-priced cosmetics in the market. Methods: Six women in their 20s and 30s with oil and moisture deficiency type dry skin were tested by dividing the cheeks into the application group of expensive marketing cosmetics and DIY cosmetics and then comparing the values of oil and moisture in these groups. Results: In the variation on the increase in oil volume after experimentation, the application group of DIY cosmetics had a statistical significance of $p=0.004$ $(" p<0.05)$, and the application group of commercial cosmetics had a significance of $p=0.002\left({ }^{*} p<0.05\right)$. Therefore, both groups showed statistically significant increases in oil content, resulting in significant increase in oil volume after experimentation. After the experiment, both groups showed a statistically significant increase in moisture $\left(p=0.001\left({ }^{*} p<0.05\right)\right.$ for the DIY cosmetics group and $p=0.000\left({ }^{*} p<0.01\right)$ for commercial cosmetics group). Conclusion: Through this study, it has been verified that there is no difference in efficacy between DIY cosmetics and expensive cosmetics, and we hope to present the development potential of DIY cosmetics that are safer and more effective through various studies in the future.
\end{abstract}

Keywords: Commercial cosmetics, DIY cosmetic, Skin oil, Skin moisture, Dry skin

\section{Introduction}

아름다움에 대한 욕구는 인류의 시작과 더불어 늘 가지고 있던 인 간의 본성이라 볼 수 있다(Song \& Kim, 2017). 더구나 경제성장과 생활소득이 향상됨에 따라 사람들의 미에 대한 관심과 욕구는 날로 증가하고 있으며 남녀노소 할 것 없이 외모를 아름답게 가꾸기 위해 노력하고 있다(Go \& Park, 2015). 아름답고 호감 있는 외모를 갖기 위한 노력은 단순하게 타인에게 좋은 인상을 주기 위함이나 스스로 에 대한 만족이라기보다는 치열해지는 경쟁구도 속에서 우위에 서 기 위한 생존에 가깝기도 하다. 보다 아름답고 개성 있게 외모 우위 에 서기 위해 많은 이들은 패션부터 헤어, 메이크업 등 다양한 방면 으로 관심과 노력을 기울이고 있다. Rho \& Kim (2014)은 최근 들
어 외모에 대한 관심이 패션에서 건강한 피부 가꾸기로 재해석되 고 있다고 주장하였으며, 특히, 안면의 피부는 함유되어 있는 수분 과 피부에서 분비되는 피지의 양에 따라 기본적으로 건성피부, 복 합성피부, 중성피부 그리고 지성 피부로 분류되어 나눌 수 있는데 (Kim \& Nam, 1995), 외부 노출이 잦고 민감해지기 쉽기 때문에 각 별히 신경을 써야 하는 신체 부위로 여성뿐만 아니라 남성들도 이에 대응책이 필요하다고 보고 있다(Kim et al., 2009). 아름답고 건강 한 피부 상태는 균형 있는 영양섭취, 적당한 수면과 운동이 동반 되 어야 하며(Lee \& Kim, 2018), 적절한 화장품의 사용은 각질층에 충 분한 유·수분을 공급해줌으로써 정상적으로 유지 될 수 있다(Rou \& Park, 2004). 건성피부는 각질층의 수분 함량이 $10 \%$ 이하로 부족 한 상태를 말하며 노화에 의해 피부 자체의 유·수분 기능 저하가 쉬 
워 주름, 피부 건조, 색소침착 등이 발생한다(Baek, 2018). 이처럼 피부에 대한 관심이 높아짐에 따라 화장품의 소비시장도 함께 급성 장하며 소비자들은 최적의 판단으로 소비를 결정하며, 자유로운 구 매 환경을 원한다(Jeong, 2018). 계절이나 연령별 화장품의 용도와 종류가 매우 다양해지고 유통의 세분화로 구매의 다양성이 추구되 어 화장품전문점이 아닌 일반 생활용품점, 약국, 면세점, 병원, 피부 관리실 등에서도 유통이 되어 지고 있다(Park \& Lee, 2015). 그 중 기초화장품은 안면에 사용되며 주로 피부의 유·수분을 유지하면서 청결과 자외선으로부터 피부를 보호해주는데 중요하고(Lim et al., 2018), 보습제는 수분을 피부표면에 공급함으로써 피부 표면의 건 조한 세포가 부드러워지고 외부로의 수분 손실을 방지하기 위한 용 도로 사용된다(Serup et al., 1989).

최근에는 단순히 수분을 보충해주는 것이 아니라 피부 장벽 기능 을 회복시켜(Lodén, 2003), 여러 피부 질환을 예방하는 중요한 기능 을 하는 것이 알려지면서 하루에도 여러 번 바르는 것이 권장되고 있 다(Park et al., 2013). 화장품의 구매 고객의 니즈가 점점 다변화, 다각화 되면서 국내화장품 시장규모는 엄청나게 커졌고, 발 빠른 무 역시장으로 고가의 외국브랜드에 잠식되어왔다(Choi, 2019). 소비자 측면에서 볼 때, 화장품은 구체적 제품의 특성 보다는 포괄적인 미 적 가치를 추구하여 구입하고 사용하기 때문에 막연한 고가이미지나 유행성을 추구하여 제품을 선택하는 일이 많고, 이는 기업으로 하여 금 제품차별화를 간과하게 만드는 원인이 되고 있다(Kim \& Choon, 2011). 고가화장품 특히 수입화장품은 수입판매 독점으로 인한 가 격경쟁력이 취약하여 갑작스러운 가격변동에도 구매자는 그대로 흡 수 할 수밖에 없는 것이 현실이다. 높은 가격에도 불구하고 아름다움 을 추구하는 필수 경향의 인식으로 구매하고는 있지만 고가임에 부 담스러워하는 것이 사실이다(Bae \& Sung, 2014). 또한, 화장품은 규제나 성분의 가이드라인이 의약품에 비해서 의존도가 낮고 생산 하는 업체의 불충분한 정보만 받아들여 사용해 오고 있는 실정이라 (Shim \& Lee, 2017) 인체에 유해한 성분들이 함유되어 있어도 소비 자들은 어쩔 수 없이 구매와 소비를 반복해 오고 있다. 이에 소비자 들은 방부제나 화학 성분의 함량을 최소화한 저자극성 화장품, 유기
농 화장품, 천연 화장품에 대해 관심을 갖게 되었으며 화장품 기업들 또한 이를 반영하여 천연화장품을 출시하기 시작하였다(Jae \& Kim, 2015). 세계적으로 천연화장품의 규모가 꾸준히 성장하고 있는 상황 에서(Kim et al., 2018) 이러한 기초 화장품의 기능을 제대로 발휘하 기 위해서는 사용방법, 계절, 생활환경, 나이, 화장품을 사용한 시기, 피부유형 및 사용목적 등이 고려되어야 한다(Lee \& Youm, 2020). 이처럼 파라벤류의 화학방부제나 계면 활성제 등의 유해성 논란은 $\mathrm{DIY}$ 화장품의 장점인 천연성분의 배합이 부각되어지면서 소비자가 직접 만들어 사용하는 DIY 화장품에 대한 관심으로 증가되었다(Lee $\& \mathrm{Kim}, 2013)$. DIY화장품에 대한 선행연구(Kim \& Yoo, 2016)에서 $\mathrm{DIY}$ 화장품은 기성의 시판화장품을 구매하기보다는 본인이 필요로 하는 원료를 선택하여 원하는 화장품을 만드는 것에 차별성을 가진 다고 할 수 있다. 이에 본 연구는 기초화장품 중 보습 에센스를 선정 하여 DIY화장품이 피부 유·수분에 미치는 변화를 고가 화장품과 비 교하여 검증함으로써 향후 미용 산업에 DIY화장품의 발전 가능성을 제시하고자 한다. 본 연구는 서비스 업종에 종사하는 20-30대 건성 피부인 여성 6 명을 대상으로 고가의 시판 화장품 에센스와 DIY화장 품 에센스를 안면부위 중 건조함이 가장 심한 볼 부위(U존)에 적용하 여 유분 및 수분 등의 피부상태의 변화를 비교 검증하여 DIY화장품 의 유효성과 발전가능성을 제시하여 화장품 산업에 유용한 기초자료 를 제시하는 것을 그 목적으로 한다.

\section{Methods}

\section{1. 연구대상 및 기간}

본 연구는 시판 화장품과 DIY화장품의 피부개선 차이를 비교하기 위해 진행하였다. 연구 대상자는 서비스업에 종사하는 20-30대 여 성 6명을 대상으로 시판화장품 적용군과 DIY화장품 적용군으로 양쪽 볼을 나누어 연구에 참여시켰다. 연구 기간은 2019년 5월 6일부터 6 월 6 일까지 4 주에 걸쳐서 진행하였다.

1) 선정기준은 아래와 같다.

\section{Table 1. Ingredients of Cosmetics}

\begin{tabular}{|c|c|}
\hline Type & Ingredients \\
\hline Cleansing foam & $\begin{array}{l}\text { Water, Aqua, EAU, Hydrogenated poly (C6-14 Olefin), Myristic acid, Lauric acid, Lauryl hydroxysultaine, Potassium } \\
\text { hydroxide, Glycerin, Stearic acid, Acrylates/C10-30 alkyl acrylate crosspolymer, Fragrance, Parfum, Limonene, } \\
\text { Hydrogenated rosin, Polyquaternium-7, Butylene glycol, PEG-14m, Disodium EDTA, Methoxy PEG-114, Poly-epsilon- } \\
\text { caprolactone, Pinus densiflora leaf extract, Sodium benzoate, Honey, Mel, Miel, Silica, 1, 2-Hexanediol, Phenoxyethanol, } \\
\text { Nelumbo nucifera flower extract, Polygonatum officinale rhizome root extract, Rehmannia glutinosa root extract, Paeonia } \\
\text { albiflora root extract, Lilium candidum bulb extract, Glycyrrhiza uralensis (Licorice) root extract, BHT, Panax ginseng root } \\
\text { extract. Pinus sy/vestris bark extract. Ethylhexylglycerin }\end{array}$ \\
\hline Brand essence & $\begin{array}{l}\text { Hyaluronic acid, Biomimetic amino acid complex, Niacinamide, Alanine, Amorphophallus konjac root powder, Aqua (Water), } \\
\text { Arginine, Aspartic acid, Biosaccharide Gum-1, Butylene glycol, Caprylyl clycol, Chondrus crispus Powder (Carrageenan), } \\
\text { Dipropylene glycol, Glycerin, Glycine, Histidine, Hydroxyethyl scrylate/Sodium scryloyldimethyl taurate copolymer, } \\
\text { Isoleucine, Methylsilanol mannuronate, Niacinamide, Parfum (Fragrance), PCA, Pentylene glycol, Phenethyl alcohol, } \\
\text { Phenylalanine polyglyceryl-4 caprate, Proline, Serine, Sodium hyaluronate, Sodium lactate, Sodium PCA, Threonine, Valine }\end{array}$ \\
\hline DIY Essence & Aloe gel, Glycerin, Wheat germ oil $(7: 2: 1)$ \\
\hline
\end{tabular}




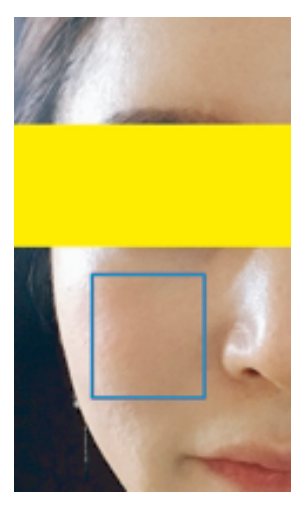

Figure 1. Region of interest area

(1) 안면 피부 질환과 피부과적 병력이 없는 자

(2) 연구기간에 별도의 피부과 및 피부 관리실 등에서 안면관리를 받지 않을 자

(3) 민감한 피부를 가지고 있지 않은 자

(4) 6 개월간 심한 필링을 하지 않은 자

(5) 연구목적을 이해하고 연구 참여에 동의한 자

\section{2. 연구방법}

\section{1) 연구재료}

클렌징 단계에서 모든 피부유형에 자극없이 사용하기 위해 $\mathrm{S}$ 사의 클렌징 폼을 선택하여 Group A, Group B 모두 동일제품을 사용하여 실험을 진행하였고. 실험에 사용된 에센스의 전 성분은 아래 Table 1 과 같다.

\section{2) 연구방법}

연구대상자들은 본 실험에 대한 목적과 실험 방법에 대한 설명과 정을 충분히 거쳐 사전 동의하에 사전 설문조사와 피부 측정에 응하 였고, 사전 설문조사는 생활 습관에 관한 인식도 6 문항으로 구성되
어있다. 실험 전 동일제품의 폼클렌징(FC:LG Life \& Health, South Korea)의 적용후 1 차로 피부 유·수분 측정을 유·수분 측정기(ICHSP001; Innoinsight INC, Korea)를 이용하여 측정하였다. 세안 후 $\mathrm{DIY}$ 에센스를 초음파 기기를 사용하여 $5 \mathrm{~min}$ 적용한 Group A (6명) 와, 시판 에센스(ES, Reviderm AG, Germany)를 초음파 기기를 사 용하여 $5 \mathrm{~min}$ 적용한 Group B (6명)를 대상으로 하였고 실험의 객 관성을 위해 홈케어시 에센스를 미사용 하게 하였다. 피부관찰은 1 주일 단위로 최소 4 주간 실시하였으며, 실험 후 피부측정은 실험 전 피부측정과 동일한 도구와 방법으로 측정하였다. 또한, 측정 부위는 Figure 1의 구역 안으로 정하였다.

\section{3) 자료처리 및 분석방법}

본 연구를 위해 실험 결과를 토대로 수집된 자료는 연구에 목적에 따라 SPSS20.0버전(Chicago, United States)을 이용하여 분석하였 다. 통계분석방법은 실험 방법 적용에 따른 실험 전후의 평균값 변화 분석을 위해 대응표본 $t$-검정을 실시하였다.

\section{Results and Discussion}

\section{1. 실험 후 유분량의 변화}

Table 2 와 Table 3 을 보면 Case 6 을 제외한 다른 실험군들이 유 분 부족형 건성이었다. DIY화장품을 적용한 Group A (좌측)의 유분 량의 변화를 보면 가장 큰 변화를 보인 경우가 Case 3 과 Case 1이었 다. Case 3 은 $+60 \mathrm{AU}$ 으로 유분이 가장 많은 증가량을 보였고 Case 1 도 $56 \mathrm{AU}$ 로 유분량이 대폭 증가하였다. 시판 화장품 에센스를 적용한 Group B (우측)의 유분량의 변화를 보면 가장 큰 변화를 보인 경우가 Case 1과 Case 3이었다. Case 1은 $58 \mathrm{AU}$ 로 유분량이 가장 많이 증 가하였으며 실험 후 두 그릅 모두 유분량의 긍정적 변화를 보여 DIY 화장품과 시판화장품의 사용은 모두 유분 부족형 건성 피부에 매우 효과적임을 알 수 있었다. Lee \& Kim (2009)의 연구에서 천연화장품 을 사용하여 유분량의 변화를 확인한 결과, 천연화장품이 유분량 증

Table 2. Comparison on individual left cheek in regards to oil content for Group A

\begin{tabular}{lccccccc}
\hline Left Cheek & Case 1 & Case 2 & Case 3 & Case 4 & Case 5 & Case 6 & Average \\
Pre-experiment (AU) & 9 & 30 & 15 & 20 & 30 & 47 & 25.16 \\
Post-experiment (AU) & 65 & 53 & 75 & 65 & 58 & 76 & 65.33 \\
Difference (AU) & +56 & +23 & +60 & +45 & +28 & +29 & +40.16 \\
\hline
\end{tabular}

Table 3. Comparison on individual right cheek in regards to oil content for Group B

\begin{tabular}{lccccccc}
\hline Left Cheek & Case 1 & Case 2 & Case 3 & Case 4 & Case 5 & Case 6 & Average \\
Pre-experiment (AU) & 7 & 45 & 25 & 7 & 25 & 50 & 26.50 \\
Post-experiment (AU) & 65 & 53 & 79 & 54 & 57 & 78 & 64.33 \\
Difference (AU) & +58 & +8 & +54 & +47 & +32 & +28 & +37.83 \\
\hline
\end{tabular}


가에 유의한 영향을 미쳤으므로 본 연구와 일치하였다. 위 결과에 따 르면 개개인으로 보았을 때 유분량의 증가의 폭이 일정하지는 않으나 평균적으로 유분량이 증가 될 것이라는 가설과 같이 실험군들이 대체 적으로 유분이 증가하는 양상을 보였으므로 에센스를 적용하는 것이 하지 않는 것보다 효과가 더 좋다는 것으로 해석할 수 있다.

실험군의 유분량 변화에 대한 결과는 Table 4 와 Table 5 와 같다. Table 4에 의하면 실험군의 실험 전·후 유분량의 평균값 분석결과 $\mathrm{DIY}$ 화장품을 적용한 Group $\mathrm{A}$ 의 경우 $t=4.922, p=0.004\left({ }^{*} p<0.05\right)$ 로, 시판화장품을 적용한 Group $\mathrm{B}$ 의 경우 $t=6.261, p=0.002$ $\left({ }^{*} p<0.05\right)$ 로 두 그룹 모두 통계적으로 유의한 결과를 얻었다. 또한 group A와 Group B의 두 그룹 간 실험 후 유분량의 변화에 대한 차 이는 Table 5 에서와 같이 $t=-0.470, p=0.658\left({ }^{*} p<0.05\right)$ 로 통계적으 로 유의한 결과를 얻지 못하여 두 그룹 간의 실험 후 유분량의 변화에 는 차이가 없음을 알 수 있었다.

\section{2. 실험 후 수분량의 변화}

Table 6과 Table 7을 보면 모든 Case가 수분 부족형 건성이었다. $\mathrm{DIY}$ 화장품을 적용한 Group A (좌측)의 수분량의 변화를 보면 가장 큰 변화를 보인 경우가 Case 1과 Case 3이었다. Case 1은 28\%로 수 분량이 가장 많이 증가하였으며 Case 3 도 $26 \%$ 로 수분량이 대폭 증 가하였다. 시판화장품을 적용한 Group A (우측)의 수분량의 변화를
보면 가장 큰 변화를 보인 경우가 Case 4 와 Case 3 이었다. Case 4는 $27 \%$ 로 수분량이 가장 많이 증가하였으며 Case 3 도 $26 \%$ 로 수분이 대 폭 증가하였다. Kim et al. (2009)의 연구에서 천연화장품을 사용하 여 수분량의 변화를 확인한 결과, 천연화장품이 수분량 증가에 유의 한 영향을 미쳤으므로 본 연구와 일치하였다. 실험 후 두 그룹 모두 수분량의 긍정적 변화를 보여 DIY화장품과 시판화장품의 사용은 모 두 수분 부족형 건성 피부에 매우 효과적임을 알 수 있었다. 위 결과 에 따르면 개개인으로 보았을 때 수분량의 증가의 폭이 일정하지는 않으나 평균적으로 수분량이 증가 될 것이라는 가설과 같이 실험군들 이 대체적으로 수분이 증가하는 양상을 보였으므로 에센스를 적용하 는 것이 하지 않는 것보다 효과가 더 좋다는 것으로 해석할 수 있다.

실험군의 수분량 변화에 대한 결과는 Table 8과 Table 9 와 같다. Table 9에 의하면 실험군의 실험 전·후 수분량의 평균값 분석결과 $\mathrm{DIY}$ 화장품을 적용한 Group $\mathrm{A}$ 의 경우 $\mathrm{t}=6.667, p=0.001\left({ }^{*} p<0.05\right)$ 로, 시판화장품을 적용한 Group $\mathrm{B}$ 의 경우 $t=9.455, p=0.000$ $\left(^{* *} p<0.01\right)$ 로 두 그룹 모두 통계적으로 유의한 결과를 얻었다. 또한, Group A와 Group B의 실험 후 수분량의 변화에 대한 차이는 Table 9 에서 보는 바와 같이 $t=-1.245, p=0.268\left(^{*} p<0.05\right)$ 로 통계적으로 유의한 결과를 얻지 못하여 두 그룹 간의 실험 후 수분량의 변화에는 차이가 없음을 알 수 있었다.

Table 4. Changes on oil content

\begin{tabular}{|c|c|c|c|c|c|c|c|}
\hline & \multirow{2}{*}{$\mathrm{N}$} & \multicolumn{2}{|c|}{ Pre-experiment } & \multicolumn{2}{|c|}{ Post-experiment } & \multirow{2}{*}{$t$} & \multirow{2}{*}{$p$} \\
\hline & & Mean & SD & Mean & SD & & \\
\hline Group A & 6 & 25.17 & 13.527 & 65.33 & 9.092 & 4.922 & $0.004^{*}$ \\
\hline Group B & 6 & 26.50 & 18.218 & 64.33 & 11.759 & 6.261 & $0.002^{*}$ \\
\hline
\end{tabular}

${ }^{*} p<0.05$.

Table 5. Difference in oil content trend and patterns

\begin{tabular}{|c|c|c|c|c|c|c|c|}
\hline & \multirow{2}{*}{$\mathrm{N}$} & \multicolumn{2}{|c|}{ Group A } & \multicolumn{2}{|c|}{ Group B } & \multirow{2}{*}{$t$} & \multirow{2}{*}{$p$} \\
\hline & & Average & Variance & Average & Variance & & \\
\hline Oil changes & 6 & 65.33 & 9.092 & 64.33 & 11.759 & 0.470 & 0.658 \\
\hline
\end{tabular}

Table 6. Comparison on individual left cheek in regards to moisture for Group A

\begin{tabular}{|c|c|c|c|c|c|c|c|}
\hline Left cheek & Case 1 & Case 2 & Case 3 & Case 4 & Case 5 & Case 6 & Average \\
\hline Pre-experiment (AU) & 21 & 30 & 27 & 28 & 30 & 34 & 28.33 \\
\hline Post-experiment (AU) & 49 & 43 & 53 & 48 & 51 & 52 & 49.33 \\
\hline Difference (AU) & +28 & +13 & +26 & +20 & +21 & +18 & +21 \\
\hline
\end{tabular}

Table 7. Comparison on individual right cheek in regards to moisture for Group B

\begin{tabular}{|c|c|c|c|c|c|c|c|}
\hline Left cheek & Case 1 & Case 2 & Case 3 & Case 4 & Case 5 & Case 6 & Average \\
\hline Pre-experiment (AU) & 19 & 33 & 29 & 19 & 29 & 35 & 27.33 \\
\hline Post-experiment (AU) & 44 & 41 & 55 & 46 & 47 & 54 & 47.83 \\
\hline Difference (AU) & +25 & +8 & +26 & +27 & +18 & +19 & +20.50 \\
\hline
\end{tabular}


Table 8. Changes on moisture content

\begin{tabular}{|c|c|c|c|c|c|c|c|}
\hline & \multirow{2}{*}{$\mathrm{N}$} & \multicolumn{2}{|c|}{ Pre-experiment } & \multicolumn{2}{|c|}{ Post-experiment } & \multirow{2}{*}{$t$} & \multirow{2}{*}{$p$} \\
\hline & & Mean & $\mathrm{SD}$ & Mean & SD & & \\
\hline Group A & 6 & 28.33 & 4.320 & 49.33 & 3.615 & 6.667 & $0.001^{*}$ \\
\hline Group B & 6 & 27.33 & 6.861 & 47.83 & 5.565 & 9.455 & $0.000^{* *}$ \\
\hline
\end{tabular}

Table 9. Difference in moisture content trend and patterns

\begin{tabular}{|c|c|c|c|c|c|c|c|}
\hline & \multirow{2}{*}{$\mathrm{N}$} & \multicolumn{2}{|c|}{ Group A } & \multicolumn{2}{|c|}{ Group B } & \multirow{2}{*}{$t$} & \multirow{2}{*}{$p$} \\
\hline & & Average & Variance & Average & Variance & & \\
\hline Moisture changes & 6 & 49.33 & 3.6155 & 47.83 & 5.565 & -1.245 & 0.268 \\
\hline
\end{tabular}

\section{Conclusion}

본 연구는 고가의 시판 화장품과 DIY화장품의 적용이 안면피부 의 유·수분 변화에 미치는 긍정적 효과를 객관적으로 비교 검증하여 화장품 산업에 DIY화장품의 발전 가능성을 제시하고자 하였다. 연 구 대상자는 유·수분 부족형 건성 피부를 가진 20대-30대의 여성 6 명을 대상으로 하여 고가의 시판화장품 적용군과 DIY화장품 적용군 으로 양쪽 볼을 나누어 실험한 뒤 유분량과 수분량의 값을 비교하여 검증하였고 그 결과는 다음과 같다.

첫째, 실험 후 유분량의 증가에 대한 변화를 알아보고자 한 결과 는 $\mathrm{DIY}$ 화장품의 적용군은 $p=0.004\left({ }^{*} p<0.05\right)$, 시판 화장품의 적용 군도 $\left.p=0.002{ }^{*} p<0.05\right)$ 이므로 두 집단 모두 유분량의 증가가 통계 적으로 유의하였고, Group $\mathrm{A}$ 는 실험전보다 실험 후 유분량이 증가 하였다. 둘째, 실험 후 Group A와 Group B의 두 그룹 간 유분량의 변화에 대한 차이를 알아보고자 한 결과는 $\mathrm{DIY}$ 화장품의 적용과 고 가의 시판화장품의 적용으로 인한 안면의 유분량의 변화가 통계적 으로 유의한 결과 $p=0.6580\left({ }^{*} p<0.05\right)$ 를 얻지 못하여 $\mathrm{DIY}$ 화장품 이 고가의 화장품과 효능에서의 차이가 없음이 검증되었고 이로써, 유분의 부족함으로 생기는 건조함에 고가의 시판화장품 뿐만 아니 라 DIY화장품 역시 효과적임을 알 수 있었다. 셋째, 실험 후 수분량 의 증가에 대한 변화를 알아보고자 한 결과는 $\mathrm{DIY}$ 화장품의 적용군 은 $\left.p=0.001{ }^{*} p<0.05\right)$, 시판 화장품의 적용도 통계적으로 유의한 결 과 $\left.p=0.000{ }^{*}{ }^{*} p<0.01\right)$ 이므로 두 집단 모두 수분량의 증가가 통계적 으로 유의하였으므로 Group A는 실험전보다 실험 후 수분량이 증 가하였다. 넷째, 실험 후 Group A와 Group B의 두 그룹 간 수분량 의 변화에 대한 차이를 알아보고자 한 결과는 DIY화장품의 적용과 고가의 시판화장품의 적용으로 인한 안면의 수분량의 변화가 통계 적으로 유의한 결과 $p=0.268\left({ }^{*} p<0.05\right)$ 를 얻지 못하여 Group A와 Group B의 수분량의 변화에 있어 차이가 없었다.

이러한 결과로 인해 DIY화장품이 고가의 화장품과 효능에서 차이 가 없음이 검증되었고 이로써, 수분의 부족함으로 생기는 건조함에 고가의 시판화장품뿐만 아니라 DIY화장품 역시 효과적임을 알 수
있었다. 이와 같은 결과를 통해 DIY화장품의 안면 피부의 유분량과 수분량의 변화에 대한 효능을 검증함으로써 DIY화장품에 의한 효용 성 가치에 높은 기대감을 보일 수 있었다. 하지만, DIY화장품은 시 장 형성의 역사가 짧고 적당한 규제나 장치가 없어서 사용의 한계점 을 가지고 있다. DIY화장품의 경우 원료를 직접 선택하고 배합 비율 등을 고려해야 함은 물론 전문적인 공정과정을 거치지 못해 자칫 제 품의 안전성에 우려가 있다. 따라서, 유효 성분에 대한 알러지나 유 해성이 보고되지 않은 부분에 대한 전문가의 조언과 더불어 각각의 유효성을 위한 다양한 성분의 연구개발이 필요하다 사료된다. 특히, 현실적으로 $\mathrm{DIY}$ 화장품의 사용이나 제작은 늘어나고 있지만 $\mathrm{DIY}$ 화 장품의 규정이나 인증기관이 없는 상태이고 재료나 성분을 판매하 는 곳의 정보로만 제작을 하고 있는 실정이다. 따라서, 향후 이러한 문제점 등을 보완하여 보다 폭넓은 표본과 다양한 성분에 대한 효능 등의 검증을 위한 연구를 통해 보다 안전하고 효과적인 DIY 화장품 의 발전가능성을 제시할 것을 기대해 본다.

\section{Author's contribution}

SL did research design, performed experiments, data collection and analysis, and wrote overall papers, and KHK did advisory. All authors read and approved the final manuscript.

\section{Author details}

Suyeun Lim (Graduate Student), Division of Beauty Arts Care, Department of Practical Arts, Graduate School of Culture and Arts, Dongguk University, 30, Pildongro 1-gil, Jung-gu, Seoul 04620 Korea; Ki Han Kwon (Professor), Division of Beauty Arts Care, Department of Practical Arts, Graduate School of Culture and Arts, Dongguk University, 30, Pildong-ro 1-gil, Jung-gu, Seoul 04620 Korea. 


\section{References}

Bae $E$, Sung $H$. The effect of price perception and product attributes on brand loyalty and repurchase intention: comparisons between high priced and low priced cosmetic brands. Korean Journal of Human Ecology, 23: 303-316, 2014.

Baek JO. Moisturizer for skin disease. The Journal of Skin Barrier Research, 20: 44-45, 2018.

Choi E. A study on the perception of the customized cosmetics and the system of preparation manager who Dispense the customized cosmetics. Journal of the Korean Society of Cosmetology, 25: 1229-1238, 2019.

Go HJ, Park SC. Effect of age on the appearance recognition by women and their appearance management behavior. Journal of Investigative Cosmetology, 11: 73-80, 2015.

Jae SM, Kim JD. A study on consumer awareness and use of organic cosmetics. Korean Society of Cosmetics and Cosmetology, 5: 151-160, 2015.

Jeong SH. Purchasing behavior for skin care products by distribution channel. Asian Journal of Beauty and Cosmetology, 16: 545-554, 2018.

Kim BH, Nam CH. A study on women's awareness of skin beauty care and make up. Korean Public Health Research, 21: 149174, 1995.

Kim GW, Choi YH, Kim BL, Kim Y, Seong RS, Han MH, Kim GA, Choi MJ, Jeong YG. Determination of anti-oxidative and whitening effects of complex extracts obtained from sprout Panax ginseng C.A. Meyer and Cassia nomame (Sieb.) Honda on skin. Asian Journal of Beauty and Cosmetology, 16: 309-320, 2018

Kim GY, Kim AK, Han SS, Lee SH. A study on the comparson of skin effects by natural cosmetics and general cosmetics. Asian Journal of Beauty and Cosmetology, 7: 225-238, 2009.

Kim $\mathrm{MH}$, Choon SH. The difference of the satisfaction level according to the shopping orientation of cosmeceuticals: focusing on whitening, sun screen, anti-aging cosmetics. Asian Journal of Beauty and Cosmetology, 9: 1-14, 2011.

Kim SR, Yoo TS. An analysis of structural relations among perception of DIY cosmetics, environmental awareness, good life-style and consuming behavior practice of consumers. Journal of Korea Design Forum, 51: 125-136,
2016.

Lee SR, Kim YS. Effect of ectoin a natural ingredient on skin hydration and skin moisture content. Asian Journal of Beauty and Cosmetology, 16: 437-447, 2018.

Lee SH, Youm D. The effects of manufacturing and sales companies and manufacturing companies' reputation and product types on the perceived product quality: focusing on cosmetic products. Journal of Digital Convergence, 18: 7181, 2020.

Lee JR, Kim JD. A study on use and satisfaction with atopic products. Korean Society of Cosmetics and Cosmetology, 3: 75-88, 2013.

Lim HS, Lee WS, Shin JW. A study on the preference of container functions for skin care cosmetics: focusing on MBTI personality types. Journal of the Korean Society of Illustration Research, 56: 73-82, 2018.

Lodén M. The skin barrier and use of moisturizers in atopic dermatitis. Clinics in Dermatology, 21: 145-157, 2003.

Park E, Kim GN, Kim HO. Effect of moisturizer containing avocado oil on the skin moisture and personal satisfaction of 20's female college students. Asian Journal of Beauty and Cosmetology, 11: 951-957, 2013.

Park EH, Lee SJ. The influence of female consumer's cosmetics purchase experience on image-making efficacy and cosmetics pursuit benefits. Journal of the Korean Fashion \& Costume Design Association, 17: 131-144, 2015.

Rho SE, Kim HS. Customer satisfaction and the intent of reutilization for the facility of general skin care and medical skin care. Journal of the Korean Society of Cosmetology, 20: 207-216, 2014.

Rou FR, Park YS. Comparison of determined skin types by different factors of facial skin hydration, sebum content and surface $\mathrm{pH}$ levels. Asian Journal of Beauty and Cosmetology, 2: 67-82, 2004.

Serup J, Winther A, Blichmann CW. Effect of repeated application of a moisturizer. Acta Dermato-Venereologica, 69: 457-459, 1989.

Shim IS, Lee HW. Research on associations with the color of a naturalism cosmetic package by each age group. The Korean Society of Science \& Art, 28: 151-162, 2017.

Song WR, Kim SA. A study on the aesthetic characteristics of sadomasochism fashion: focused on cases since 2000. Journal of Fashion Design, 17: 105-121, 2017. 


\section{시판화장품과 DIY화장품이 20-30대 건성피부여성의 유·수분 변화에 미치는 영향에}

\section{관한 연구}

임수연, 권기한

동국대학교 문화예술대학원 실용예술학과 뷰티아트케어전공, 서울, 한국

목적: 내적인 건강과 외적인 아름다움에 대한 기대치가 향상됨에 따라 천연 제품을 이용한 스킨케어에 대한 관심이 더 높아지고 소 비가 증가되면서 Do It Yourself (DIY) 화장품 시장에도 영향을 미치게 되었다. 최근 "맞춤형 화장품 조제관리사" 국가자격증이 생 길 정도로 DIY화장품은 소비자의 니즈를 반영하는 최근 트랜드가 맞물려 있다. 이에 본 연구는 스스로 만들어 쓰는 DIY화장품의 효 과를 시중의 고가 화장품과 비교·분석하는 실험을 통하여 DIY 화장품의 향후 발전 가능성을 제시하고자 하였다. 방법: 유·수분 부족 형 건성 피부를 가진 20 대-30대의 여성 6 명을 대상으로 하여 고가의 시판화장품 적용군과 DIY화장품 적용군으로 양쪽 볼을 나누 어 실험한 뒤 유분량과 수분량의 값을 비교하여 검증하였다. 결과: 실험 후 유분량의 증가에 대한 변화에서는 $\mathrm{DIY}$ 화장품의 적용군 은 $p=0.004$ ( $\left.{ }^{*} p<0.05\right)$, 시판 화장품의 적용군도 $p=0.002\left({ }^{*} p<0.05\right)$ 이므로 두 집단 모두 유분량의 증가가 통계적으로 유의하게 나타 나 두 그룹 모두 실험 후 유분량이 유의적으로 증가하였다. 실험후 수분량의 변화를 알아보고자 한 결과에서는 $\mathrm{DIY}$ 화장품의 적용군 $p=0.001$ ( ${ }^{*} p\langle 0.05)$, 시판 화장품의 경우 $p=0.000$ ( ${ }^{*} p<0.01$ )로 두 집단 모두 수분량의 증가가 통계적으로 유의하게 나타나 두 그룹 모두 실험 후 수분량은 유의적으로 증가하였다. 결론: 이와 같은 결과를 통해 $\mathrm{D} Y$ 화장품의 안면 피부의 유분량과 수분량의 변화에 대한 효능을 검증함으로써 DIY화장품에 의한 효용성 가치에 높은 기대감을 보일 수 있었다. DIY화장품의 경우 원료를 직접 선택하 고 배합 비율 등을 고려해야 함은 물론 전문적인 공정과정을 거치지 못해 자칫 제품의 안전성과 안정성을 장담할 수 없을 우려가 있 다. 따라서, 향후 이러한 문제점 등을 보완하여 보다 폭넓은 표본과 다양한 성분에 대한 효능 등의 검증을 위한 연구를 통해 보다 안 전하고 효과적인 DIY 화장품의 발전가능성을 제시할 것을 기대해 본다.

핵심어: 시판화장품, DIY화장품, 유수분 변화, 건성피부, 안면 유분

\section{참고문헌}

고희자, 박순천. 여성의 연령별 외모인식 및 외모관리 행동에 관한 연구. 대한미용학회지, 11: 73-80, 2015.

김건우, 최윤희, 김병록, 김영욱, 성락선, 한민희, 김경애, 최민주, 정용기. 새싹인삼과 차풀 복합추출물의 피부 항산화 및 미백효과. 아시안뷰티화장품학술지, 16: 309-320, 2018.

김기연, 김애경, 한성수, 이승화. 천연화장품과 일반화장품의 피부효능비교연구: 벨모나 천연화장품을 중심으로. 아시안뷰 티화장품학술지, 7: 225-238, 2009.

김명희, 황춘섭. 기능성화장품 구매성향에 따른 소비자 만족도: 미백개선제, 자외선차단제, 주름개선제. 아시안뷰티화장품

학술지, 9: 1-14, 2011.

김복희. 여성의 피부 미용관리와 화장실태에 관한 조사연구. 대한보건연구, 12: 149-174, 1995.

김선령, 유태순. 소비자의 DIY 화장품 인식, 환경의식, 착한 라이프스타일, 소비실천행동 간의 구조적 관계. 한국디자인포

럼, 51: 125-136, 2016.

노상은, 김현서. 일반피부관리와 메디컬 피부관리에 대한 만족도 및 재이용의도. 한국미용학회지, 20: 207-216, 2014. 류희라, 박영숙. 안면 유분량, 수분량 및 $\mathrm{pH}$ 기준에서의 피부유형 판정 비교. 아시안뷰티화장품학술지, 2: 67-82, 2004. 박은아, 김교남, 김혜옥. 20 대 여성을 대상으로 한 아보카도 오일 함유 보습제의 만족도 및 피부 보습에 미치는 효과. 아시

안뷰티화장품학술지, 11: 951-957, 2013. 
박은희, 이상주. 여성소비자의 화장품 구매 체험이 이미지메이킹 효능감과 화장품추구혜택에 미치는 영향. 한국의상디자인 학회지, 17: 131-144, 2015.

배은정, 성희원. 가격인지차원과 제품 속성이 브랜드 충성도와 재구매의도에 미치는 영향: 고가와 저가 화장품 브랜드 비 교. 한국생활과학회지, 23: 303-316, 2014.

백진옥. 보습제와 피부질환. 한국피부장벽회지, $20: 74,2018$.

송우리, 김선아. 사도마조히즘 패션의 미적 특성 연구: 2000 년대 이후 사례를 중심으로. 한국패션디자인학회지, 17 : 105-121, 2017.

심인숙, 이혜원. 자연주의 화장품 패키지 컬러에 대한 연령별 연상에 관한 연구. 한국과학예술융합학회, 28: 151-162, 2017.

이정림, 김주덕. 아토피 제품의 사용실태와 만족도에 관한 연구. 한국화장품미용학회지, 3: 75-88, 2013.

이새롬, 김영삼. 천연성분 Ectoin이 피부 보습 및 수분에 미치는 영향. 아시안뷰티화장품학술지, 16: 437-447, 2018.

이수행, 염동섭. 제조판매원과 제조원의 명성 및 제품유형이 지각된 품질에 미치는 영향: 화장품을 중심으로. 디지털융복 합연구, 18: 71-81, 2020.

임희숙, 이우식, 신재욱. 기초화장품 용기 기능의 선호도 연구: MBTI 성격유형을 중심으로. 일러스트레이션 포럼, 56 : 73-82, 2018.

정선희. 유통채널별 기초화장품 구매행동. 아시안뷰티화장품학술지, 16: 545-554, 2018.

제수민, 김주덕. 유기농화장품에 대한 소비자인식 및 사용실태에 관한 연구. 한국화장품미용학회지, 5: 151-160, 2015. 최에스더. 맞춤형 화장품과 맞춤형화장품조제관리사 제도에 관한 인식도 조사. 한국미용학회지, 25: 1229-1238, 2019. 


\section{中文摘要}

\section{商业品牌化妆品和DIY化妆品对20-30多岁皮肤干燥的女性的油/水分变化的影响}

林秀奸，權起漢*

东国大学文化艺术大学院实用艺术学科美容艺术护理专业，首尔，韩国

目的：随着人们对护肤和天然产品消费的兴趣增加，对内部健康和外部美容的期望的提高也影响了（DIY化妆品 市场。因此, 本研究旨在通过比较和分析公司自身生产的DIY化妆品与市场上高价化妆品的效果的实验, 来提 供DIY化妆品未来发展的可能性。方法：通过将脸颊分为昂贵的市场营销化妆品和DIY化妆品的应用组, 然后比 较这些组中的油和水分值, 对20-30多岁的缺油和缺水型干性皮肤的6位女性进行了测试。结果: 在实验后, 油 量增加的变化中, DIY化妆品的应用组的统计学意义为 $p=0.004 （ " p<0.05 ）$ ，而商业化妆品的应用组的意义为 $p=0.002 （{ }^{*} p<0.05 ）$ 。因此, 两组均显示出统计学意义上的油含量显着增加, 导致实验后油量显着增加。实 验后, 两组均显示出统计学上显着的水分增加（DIY化妆品组为 $p=0.001 （ " p<0.05 ）$ ，商业化妆品组为 $p=0.000$ （ $p<0.01 ） 。$ 结论: 通过研究, 已证实DIY化妆品和昂贵化妆品之间的功效没有差异, 我们希望通过今后的各种 研究来展示更安全, 更有效的DIY化妆品的发展潜力。

关键词：商业化妆品，DIY化妆品，皮肤油，皮肤水分，皮肤干燥 
